\title{
Statistical Analysis of Image with Various Noises and Filters
}

\section{Sajid Ali khan 1, ${ }^{*}$, Uzma Sadiq ${ }^{2}$, Sayyad Khurshid ${ }^{3}$}

${ }^{1}$ Green Hills Postgraduate College Rawalakot Azad Kashmir, Pakistan

${ }^{2}$ University of Kotli Azad Kashmir, Pakistan

${ }^{3}$ Govt. Postgraduate College Boys Rawalakot Azad Kashmir, Pakistan

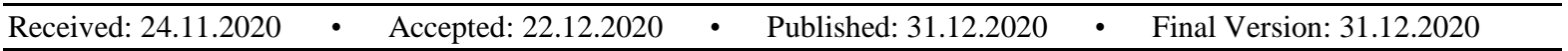

\begin{abstract}
Research displays an extensive investigation for different factual statistical estimates and their practical implementation in picture handling with various noises and filter channel procedures. Noise is very challenging to take out it from the digital images. The purpose of image filtering is to eliminate the noise from the image in such a way that the new image is detectible. We have clarified different calculations and systems for channel the pictures and which calculation is the best for sifting the picture. Signal and maximum Peak proportion parameters are utilized for execution for factual estimating, Wiener channel performs preferred in evacuating clamor over different channels. Wiener channel functions admirably for a wide range of clamors. The exhibition of Gaussian channel is superior to anything Mean channel, Mask Filter and Wiener channel as per MSE results. In picture setting up, a Gaussian fog generally called Gaussian smoothing is the result of darkening an image by a Gaussian limit. We reason that Gaussian separating approach is the best method that can be effectively actualized with the assistance of the MSE of picture. The Gaussian channel is certifiably superior to different calculations at expelling clamor. The outcomes have been looked at for channels utilizing SNR, PSNR and Mean Square Error esteem.
\end{abstract}

Keywords: Key words: SNR, PSNR, MSE

\section{Introduction}

Statistical measurements are the investigation of the social occasion, organization, examination, and translation of actualities. It offers with all components of this, remembering the arranging of measurements assortment for expressions of the plan of overviews and analyses.

The assorted factual measures are engaging and inferential. Statistical estimates are widely effective with broad scope for logical and investigation of social examinations, which incorporates: medical statistics, pc, science, human science, social mechanical skill, brain research and social investigations and so forth.

We have contemplated various sort of factual measures in regard to picture preparing and mimicked those. Fundamental intention of this goal is utility of statistical estimates for different areas of photograph preparing such as, picture noising, photo de-noising or sifting, etc. On the essential stage and facilitate the decision of factual generally speaking execution for a specific photograph handling strategy.

\footnotetext{
* Corresponding Author: sajid.ali680@gmail.com
} 


\subsection{Noise}

In all actuality, each caught photo consolidates commotion. Because of different obstructions, clamor, the photo definition gets horrendous effect. At the equivalent time, clamor making the photo obscured. The terrible situation changed into submerged totally. It offers examination huge trouble. Subsequently, individuals need to smother unwanted clamor to improve picture top notch.

Clamor is an arbitrary variant of picture force and unmistakable as grains in the picture. Commotion technique, pixels in the photo present one of kind profundity esteems instead of exact pixel esteems. Commotion starts from the physical idea of identification strategies and has numerous exceptional administration and causes.

Clamor can explain comprehended with boundary for vibe formula acquired stock measurements for secure components. That is, a high contrast photo, the photo pixel brilliance conveyance are accepted. At that point the obstruction it gets from the splendor dispersion of highlight can be known as photo commotion. In any case, the clamor in statute can be depicted as eccentric. It might be utilized factual systems to perceive the probability of irregular blunders. Thusly, the photograph commotion as a multidimensional irregular contraption is suitable. Along these lines, it can be characterized commotion is really irregular device can acquire the depiction which utilizes the probability appropriation highlight and peril thickness work. In any case, generally, this portrayal might be entangled (Gopatoti, Gopathoti, Shanganthi, \& Nirmala, 2018).

\section{Review of Literature}

Kaur S. (2015) sent visual computerized pictures are a significant issue in the cutting edge information correspondence organize. The pictures sent through the orignal sender point sometime not equivalent as compared the less than desirable point. The picture acquired after transmission is frequently tainted with clamor. A clamor is presented in the transmission medium because of an uproarious channel, mistakes during the estimation procedure and during quantization of the information for advanced stockpiling. The picture got at the less than desirable end needs preparing before it tends to be utilized for additional applications. To reestablish the first picture at the collector end is the difficult errand for the specialists. Clamor can corrupt the pictures at the hour of catching or transmission of the picture.

Rashidi \& Rahimz (2016) underscored the apparatus of the fundamental picture statics for picture reclamation, de-obscuring, de-noising, upgrade, edge location, edge honing, discovering edge location and a lot basic level of root machines with picture handling of PC. Fondamental assessment with investigation for reclamation, no scuring and filtering, various clamor models were talked about, afterward statistical findings for aftereffects of measurements, different measure for various sorts of commotion had positively added with picture, afterward the procedure for filters with well performance of examination shows well impact.

Arya \& Semwal (2017) investigated picture is an inclined which have an assortment of clamor is Digital pictures. for example Poisson commotion, Gaussian clamor. To get critical outcomes, Filters like Median channels, Averaging channels and Weiner channel have been proposed to expel commotion from Lung Images .This Paper manages correlation of different channels for clamor expelling by book keeping ratios and errors as execution parameters.

Gopatoti et al. (2018) examined the various kinds of clamor will influence the nature of the pictures and the data in pictures. As a cure, the charming and the realities from the noised picture might be recovered by the utilization of restrictive styles of channels. On this work Gaussian clamor, 
indiscreet commotion, spot commotion, and poisson clamor are being considered and it can be diminished utilizing a Gaussian channel, Wiener channel, Mean channel and middle channel. The Transforms like wavelets, Contourlet, and curvelet that assume the significant job in picture denoising are additionally displayed. The trial final product shows the exhibition of different assortments of channels and changes to denoise the noised pictures from restrictive sorts of clamors.

\section{Methodology}

During picture procurement or transmission, a few components are at risk for presenting commotion inside the image. Depending at the types of unsettling influence, the commotion can affect the picture to various volumes. Our transcendent test is to discard specific sort of clamor. So we should initially choose sure kind of commotion and watch unmistakable calculations to push off the clamor. Types of some basic noise are:

\subsection{Gaussian Noise}

Gaussian commotion is gently apportioned over sign. Along these lines that each pixel of photo is uproarious photograph of aggregate for original pixel cost with assumed normal dispensed to noise. The commotion is impartial of profundity of pixel cost at each factor. An exceptional problem of commotion is white noise, wherein few qualities of two times were indistinguishably administered with factually fair-minded. Repetitive sound its call from white mellow. Head assets of Gaussian commotion in computerized photos go to bat for the span of securing, for instance sensor clamor on account of awful light or extreme temperature or transmission (Arya \& Semwal, 2017).

$$
P(x)=\frac{1}{\sqrt{2 \pi \sigma^{2}}} e^{-\frac{1}{2 \sigma^{2}}(z-\theta)^{2}}
$$

\subsection{Salt and Pepper Noise}

This clamor of commotion is motivational. This noise is truly the force of piece spikes with sharp points. This kind for clamor is growing because of blunders information. These clamor events occur inside the photo in view 'sharp' and unexpected adjustments with picture sign. The photographs debased by the method for 'salt and pepper' clamor the boisterous pixels of photo can take best and most important basic qualities inside the dynamic assortment. It is seen that eight-piece photograph, the standard incentive for pepper commotion is 0 and salt clamor is 255 . Commotion of 'salt and pepper' is the most important part of direct result for failing of pixel factors inside the digicam sensors, defective memory areas or timing botches inside the digitization framework (Rashidi \& Rahimz, 2016).

$$
P(x)= \begin{cases}P a, x=a \\ P b, x=b\end{cases}
$$

Here, one is for bright vicinity known as ' $a$ ' and any other one is darkish place called ' $b$ '.

\subsection{Speckle Noise}

This type of commotion is multiplicative dot as compared to previous discuss noises. Speckle clamor can demonstrated by method for irregular cost augmentations as picture pixel estimations is communicated below 


$$
P=I+n * I
$$

Where 'P' clamor photo, 'I' enter photo and ' $\mathrm{n}$ ' uniform clamor photograph with zero and ' $\mathrm{v}$ ' variance.

This dot typically found with detecting machine, despite the fact that it can present in any different type for remotely detected photograph uses with intelligent radiation of clamor. The laser light for waves of clamor produced by utilizing fiery sensors venture in area and has association insignificantly their objective filed. Lessening the main effect for dot clamor allows in both higher segregation of scene goals and simpler computerized photo division (Boyat \& Joshi, 2015).

\subsection{Poisson Noise}

'Poisson' clatter or disturbance is uncommon sort of electronic uproar that happens when the set number for particles that pass on imperativeness, for instance, electrons of clamor with system or photons in any other optical device, is adequately small to offer rising to recognizable verifiable fluctuations in statistical estimation.

This sort of commotion is brought about for non-linear function of photo identifiers and recorders. Here the picture information subordinate term emerges on the grounds that location also, recording structures incorporate discretionary electron transmission having Poisson scattering with mean response regard. Since the mean and variance of Poisson spread are identical, the sign ward term has a standard deviation on the off chance that it is accepted that the clamor has a solidarity change. This clamor influences the regular pictures (Gopatoti et.al. 2018). The distribution function of Poisson is

$$
f(x)=\frac{\theta^{x} e^{-\theta}}{x !}
$$

\section{Filters}

Picture de-noising is significant undertaking in picture preparing for the investigation of pictures. One objective in picture reclamation is to expel the clamor from the picture so that the first picture is noticeable. In present day advanced picture preparing information de-noising is an outstanding issue and it is the worry of different application territories. Picture filters are regularly utilized in specific area of image or distributing the picture was some way or another debased yet should be improved before it very well may be printed. At the point, we used the specific functional form of debasement procedure; the converse procedure easily applicable to specific picture to reestablish backward to first structure (Kumar \& Gupta, 2012).

For advanced picture commotion decrease, the fundamental sifting calculations are utilized. It incorporates statistical average, Gaussian normal, mask and Wiener filtering of photo.

\subsection{Mean Filter}

The mathematical average, also known as arithmetic mean channel, works on a sliding window for computing to normal for total pixel esteems inside sliding window, and supplanting for middle pixel esteem to respective goal picture from outcome. Its scientific definition is given as follows:

$$
A \cdot M=\frac{\sum_{i=1}^{k} X}{k}
$$

The math mean filter makes a specific measure of obscuring the picture, accordingly diminishing the impacts of clamor and nearby varieties. It tends to be utilized to diminish clamor of various kinds. 
The ordinary channel having different works by going through the image 'pixel by pixel' overriding each a motivating force with the typical advantage for nearest pixels of photos, including from it (Chandel \& Gupta, 2013).

\subsection{Gaussian Filter}

Gaussian separating is utilized to obscure pictures and expel commotion and detail. Gaussian is also known as direct filter channel (Makandar \& Halalli, 2015). It's generally utilizing the picture to minimize clamor. On the off chance that you utilize one of the two with distributed, you can easily use to "unsharp veiling". The single channel also decreases the clamor. In one measurement, the Gaussian capacity is:

$$
g(x)=\frac{1}{\sqrt{2 \pi \sigma^{2}}} e^{-\frac{1}{2 \sigma^{2}} x^{2}} \quad,-\infty<x<\infty
$$

With zero mean and variance $\sigma^{2}$

\subsection{Mask Filter}

In picture handling, a part, convolution network, or veil is a little framework. It is utilized for obscuring, honing, decorating, edge identification, and that's only the tip of the iceberg. This is practiced by doing a convolution between a bit and a picture.

\subsection{Wiener Filter}

The type of channel is estimated to 'Norbert Wiener' during 1940s and published in 1949. The existence of clamor present in a sign from covariance and correlation findings to the ideal sign. 'Wiener channel' is definitely not a flexible direct considering the way that the theories behind the concept of this filter acknowledge that the information resources are known as stationary (Mistry \& Banerjee, 2014). The target of the Wiener filter through the channel is upheaval that has contaminated a specific sign. It relies upon a quantifiable procedure. Common channels are proposed for a perfect repeat response. In any case, the arrangement of the Wiener channel receives a substitute procedure. One is relied upon to think about the appalling properties from primary sign with disturbance, and once searches for trend line invariant filter that comes as close to the main sign with sensibly be normal. The Wiener filter is:

$$
P(x, y)=\frac{H^{\tau}(x, y)}{|H(x, y)|^{2}+\frac{K_{n}(x, y)}{K_{S}(x, y)}}
$$

Where: $H(x, y)=$ Degeneration word

$H^{\tau}(x, y)=$ Difficult debase work

$K_{n}(x, y)=$ White crash

$K_{s}(x, y)=$ White crash diminishing of photos

\section{Performance of Statistical Measures}

\subsection{Signal to Noise Ratio}

Signal extent takes a gander at the level of needed sign into level for establishment racket (Boyat \& Joshi, 2015). The higher the proportion, the less prominent the foundation clamor is:

$$
S N R=\frac{P_{\text {signal }}}{P_{\text {noise }}}
$$




\subsection{Mean Square Error}

Mean Square Error (MSE) indicates the total errors identifying with acknowledgements alongside from exceptional picture (Patidar, Lalit, Singh, \& Bagaria, 2014).

Where: $f(i, j)=$ Original data of photo

$$
M S E=\frac{1}{m n} \sum(f(i, j)-g(i, j))^{2}
$$

$g(i, j)=$ Debase data of photo

$\mathrm{m}$ and $\mathrm{n}$ are quantities of lines and sections of photo pixels.

\subsection{Peak Signal to Noise Ratio}

PSNR is numerical estimation from boisterous picture regarding that of the first picture. This extent is normally used as photo quality measurements among the original and debase photo. The measurements of PSNR, the good estimates are the idea of the new photo (Kaur \& Singh, 2011).

$$
P S N R=20 \log _{10}\left(\frac{M A X f}{\sqrt{M S E}}\right)
$$

Here MAXf is the high quantity of photo.

\section{Results and Discussions}

\subsection{Noise}

Noise is consistently exhibits in pictures during picture procurement, coding, transmission, and preparing steps. Clamor is extremely hard to expel it from the advanced pictures without the earlier information on commotion model. The near examination has been displayed based on various noise for the first picture, which is appeared in the beneath.
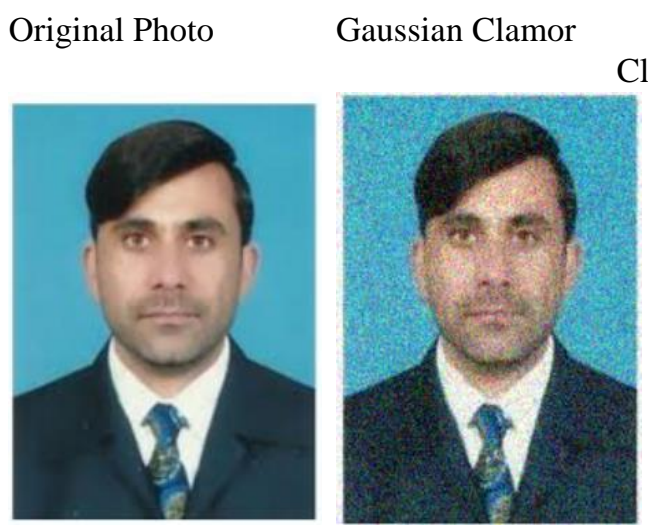

Salt \& Pepper

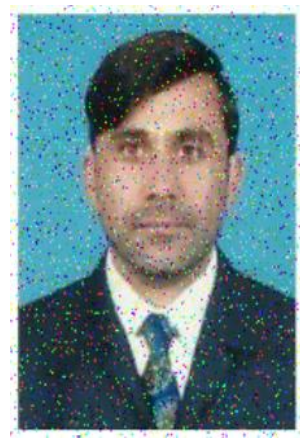

Table 1.

\section{Noise Image}

Gaussian Noise

Salt \& Pepper

Speckle Noise

Poisson Noise
SNR

17.7917

14.2890

15.5482

24.3238
Speckle Clamor

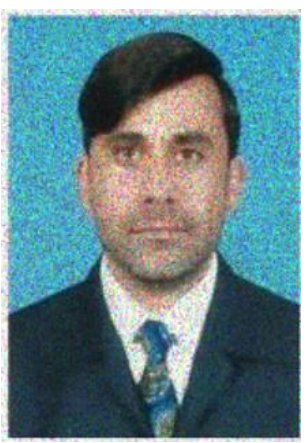

Poisson Clamor

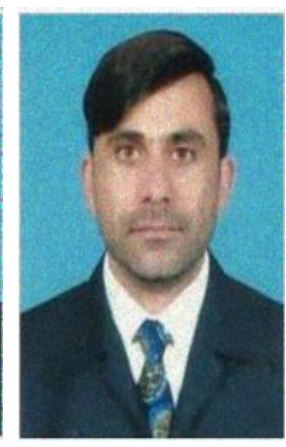

MSE

525.7995

20.9226

1220.1220

839.6570

18.8898

27.4200

117.7837 


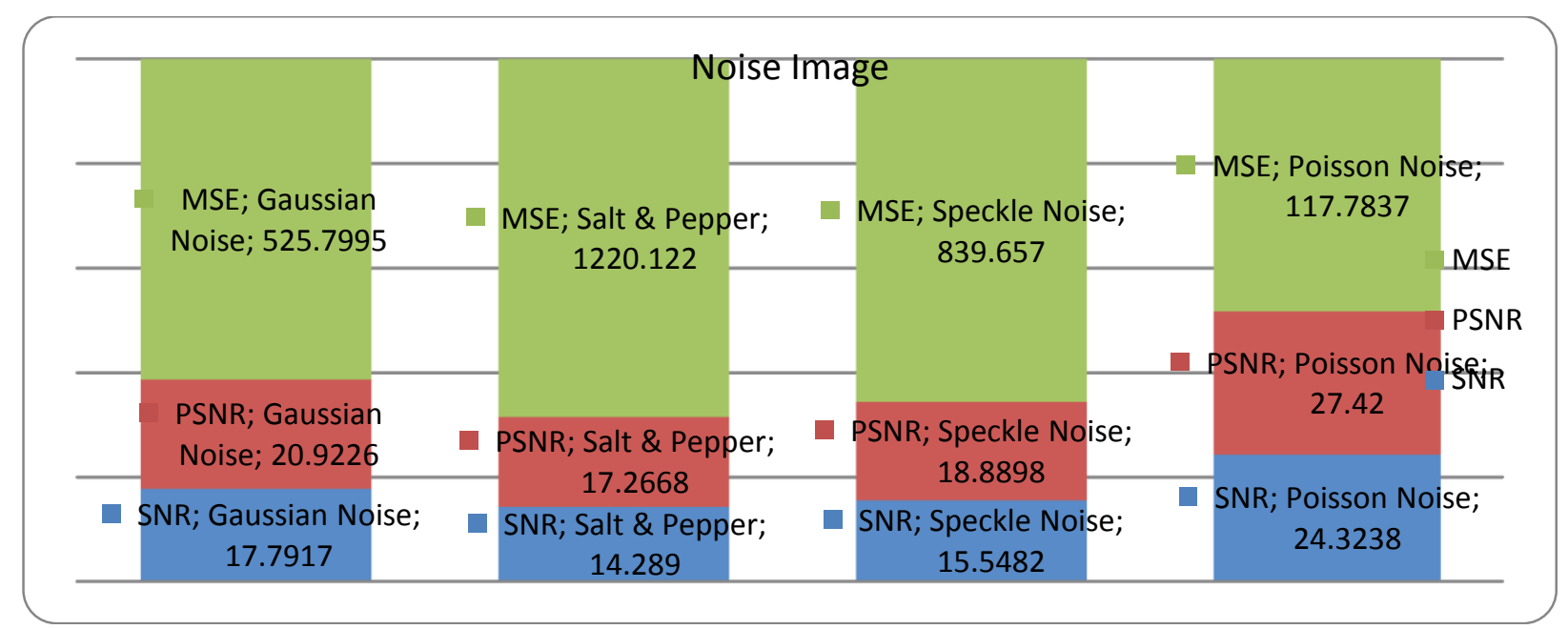

We express detail information of different commotion noise models. These commotion models can be chosen by investigation of their starting point. Right now, present a total and quantitative investigation of Gaussian, Salt and Pepper, Speckle and Poisson of the clamor picture utilizing SNR, PSNR and MSE in table (1).

\subsection{Filter}

The basic numerical results are introduced which investigated the attributes of the different channels utilized and tried. Separating assists with improving the picture by expelling clamor. The outcome is taken by looking at the exhibition of Mean, Gaussian, Mask and Wiener based on SNR, PSNR and MSE esteem.
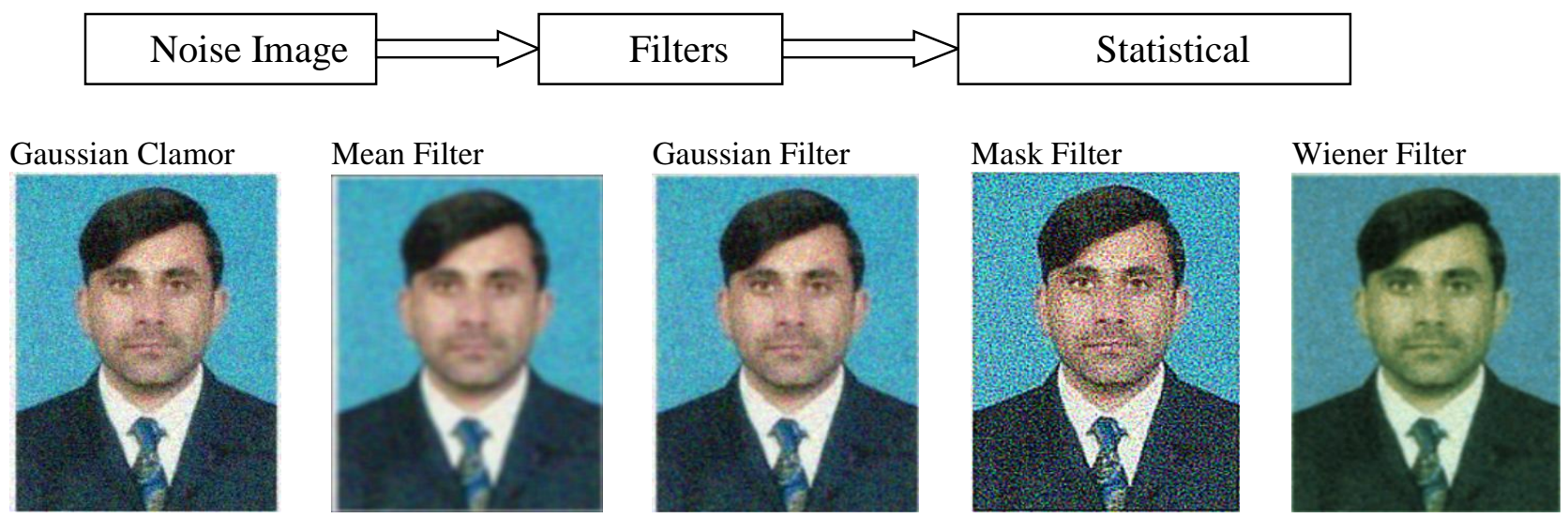

Figure 1. Gaussian Clamor with Filters 


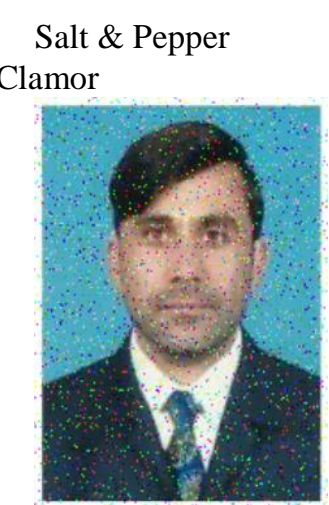

Mean Filter

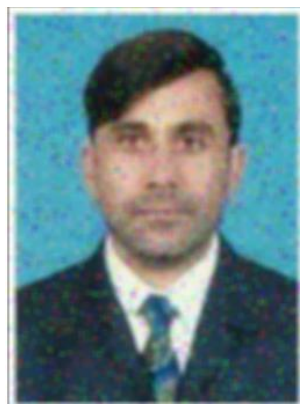

Figure 2. Salt \& Pepper Clamor with Filters
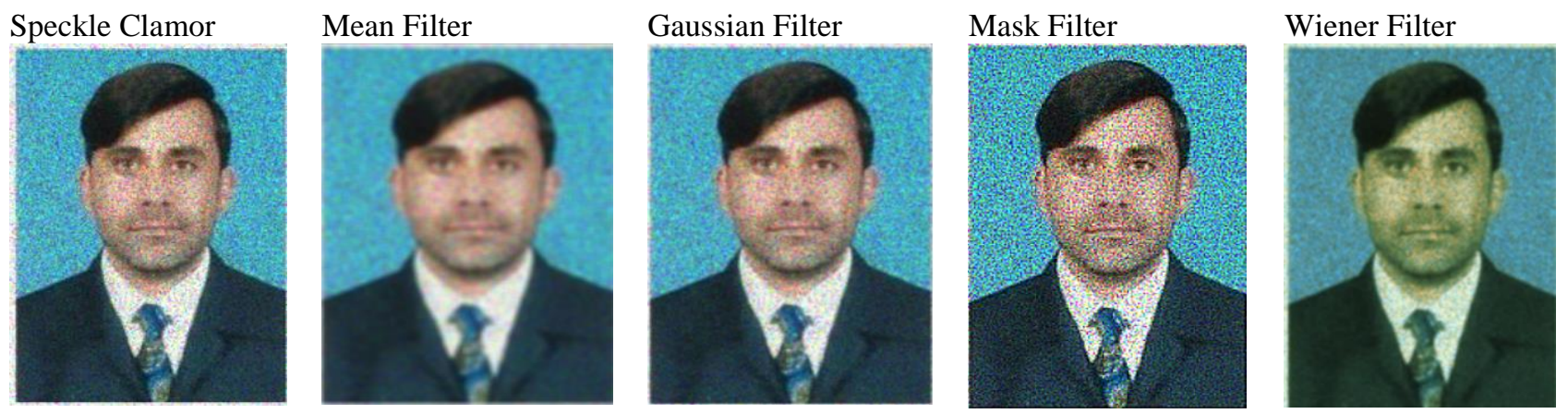

Figure 3. Speckle Clamor with Filters
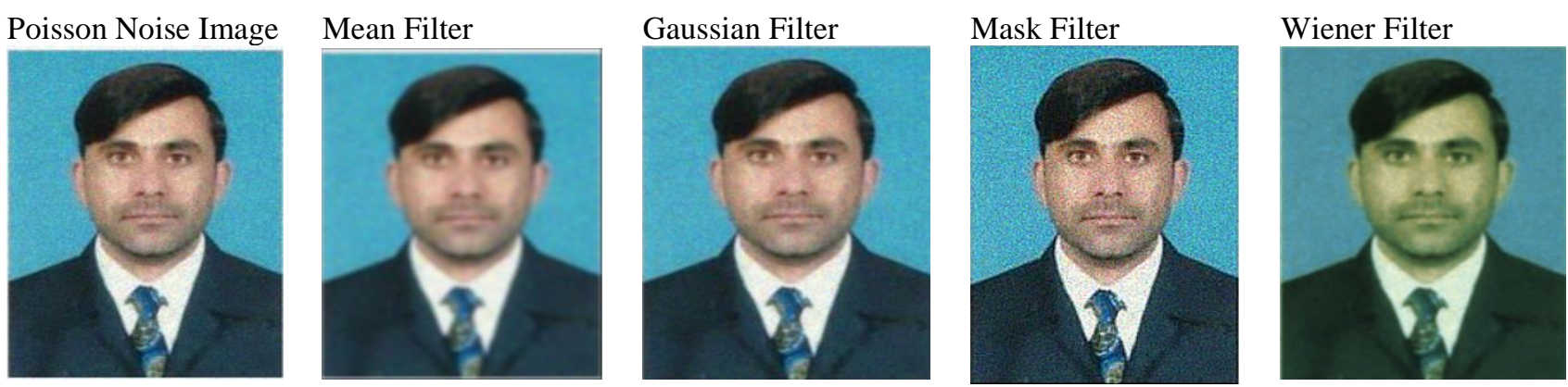

Figure 4. Poisson Noise Image with Filters

Table 2. SNR of Noise Image with Different Filters

$\begin{array}{lccccc}\text { Noise Image } & \text { Noise } & \text { Mean Filter } & \begin{array}{c}\text { Gaussian } \\ \text { Filter }\end{array} & \text { Mask Filter } & \text { Wiener Filter } \\ \text { Gaussian } & 17.7917 & 13.9747 & 26.1360 & 11.6523 & 12.9465 \\ \text { Salt \& Pepper } & 14.2890 & 14.9001 & 26.9184 & 15.5287 & 12.7677 \\ \text { Speckle Noise } & 15.5482 & 15.6413 & 27.9140 & 12.7888 & 13.4654 \\ \text { Poisson Noise } & 24.3238 & 16.7543 & 29.7624 & 17.4187 & 14.1209\end{array}$




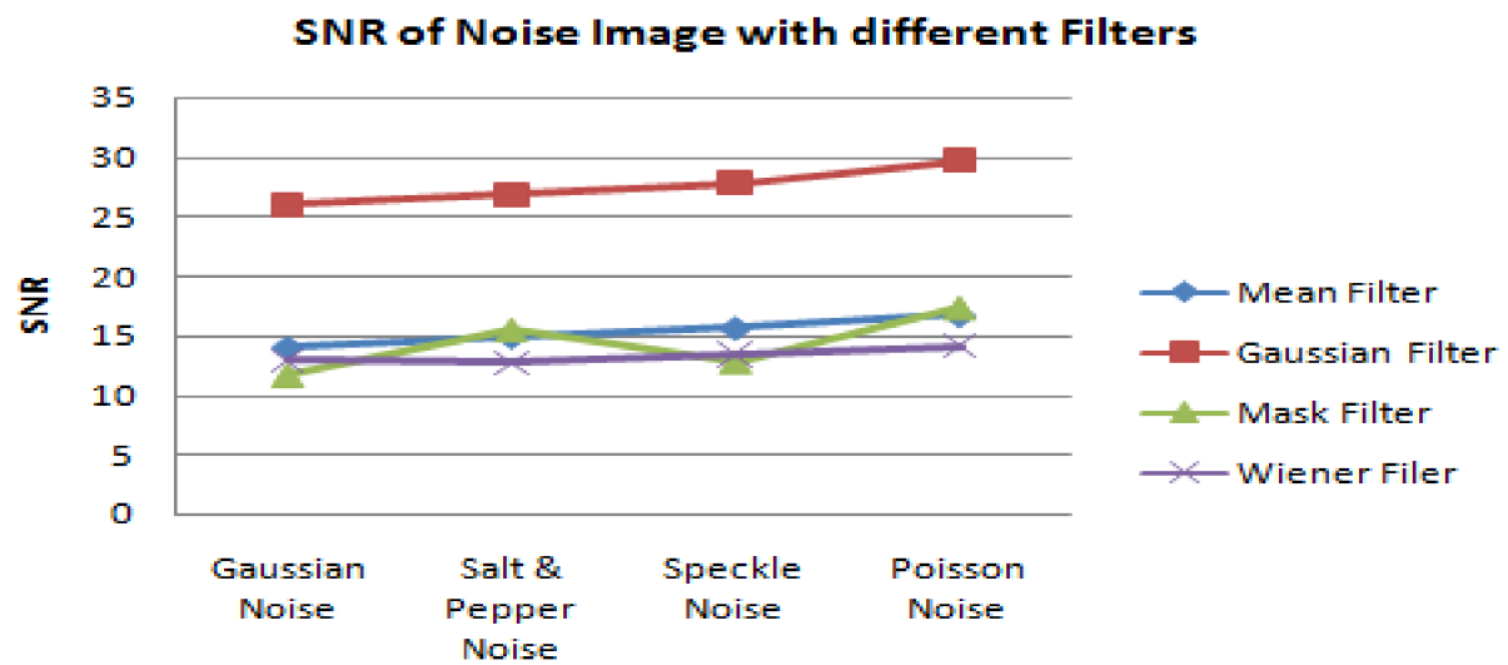

Figure 5.

In table (2), Signal to Noise Ratio shows Wiener channel performs preferable in evacuating commotion over different channels. Mask channel likewise give better outcomes to evacuating commotion just Gaussian clamor picture. Mean channel is superior to just Gaussian Filter.

Table 3. PSNR of Noise Image with Different Filters

$\begin{array}{lccccc}\text { Noise Image } & \text { Noise } & \text { Mean Filter } & \begin{array}{c}\text { Gaussian } \\ \text { Filter }\end{array} & \text { Mask Filter } & \text { Wiener Fil } \\ \text { Gaussian } & 20.9226 & 19.7067 & 31.5964 & 16.5489 & 19.6053 \\ \text { Salt \& Pepper } & 17.2668 & 20.1396 & 31.8926 & 20.1522 & 18.9244 \\ \text { Speckle Noise } & 18.8898 & 21.3111 & 33.3635 & 17.9271 & 20.0887 \\ \text { Poisson Noise } & 27.4200 & 22.5117 & 35.3400 & 22.8008 & 20.8571\end{array}$

PSNR of Noise Image with different Filters

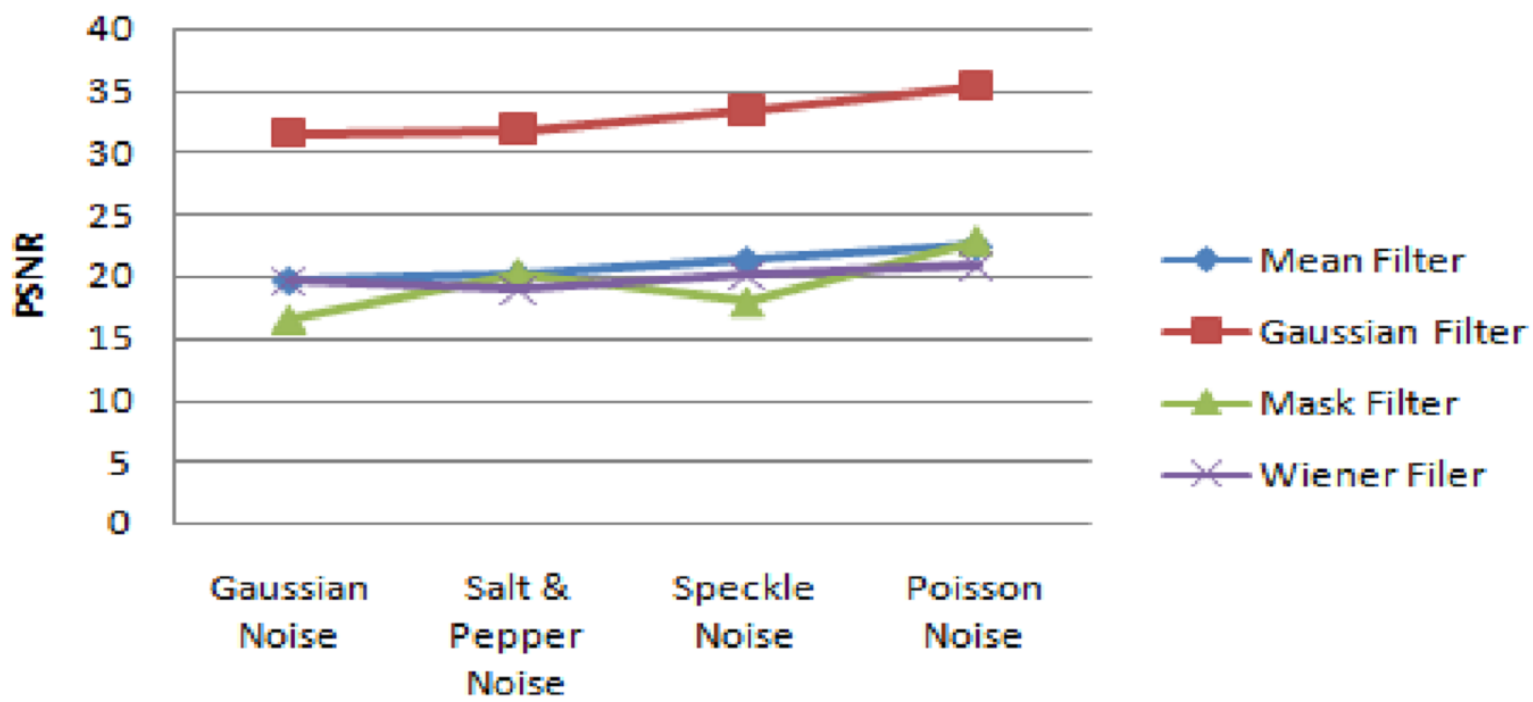

Figure 6.

The Peak Signal to Noise proportion estimator is utilized to estimating the adequacy everything being equal. Each kind of channel works diversely on various sorts of commotions. Wiener channel 
functions admirably for a wide range of clamors where as Mask channel functions admirably for evacuating Gaussian and speckle noise and the Mean channel functions admirably when contrasted with Gaussian channel from table (3).

Table 4. MSE of Noise Image with Different Filters

$\begin{array}{llcccc}\text { Noise Image } & \text { Noise } & \text { Mean Filter } & \begin{array}{c}\text { Gaussian } \\ \text { Filter }\end{array} & \text { Mask Filter } & \text { Wiener Filter } \\ \text { Gaussian } & 525.7995 & 695.6854 & 45.0232 & 1439.4320 & 712.1208 \\ \text { Salt \& Pepper } & 1220.1220 & 629.6807 & 42.0549 & 627.8546 & 832.9966 \\ \text { Speckle Noise } & 839.6570 & 480.8089 & 29.9730 & 1048.0237 & 637.1017 \\ \text { Poisson Noise } & 117.7837 & 364.6795 & 19.0144 & 341.1967 & 533.7921\end{array}$

MSE of Noise Image with different Filters

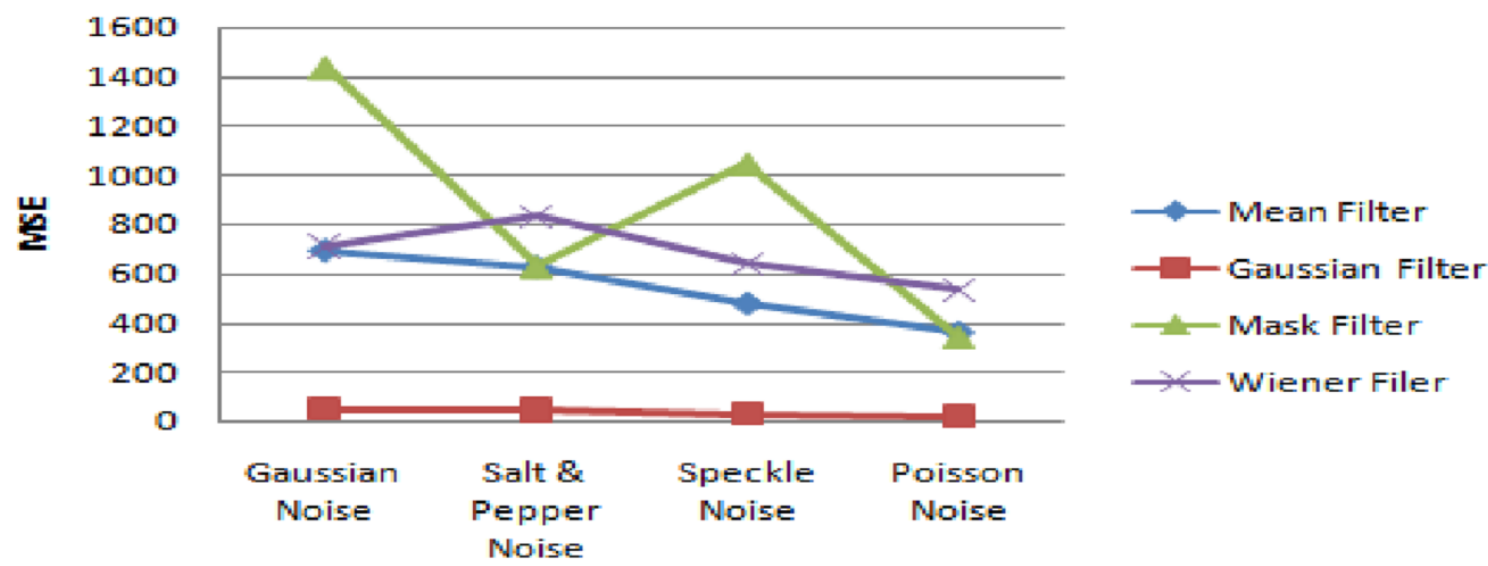

Figure 7.

The presentation of Gaussian channel is superior to anything Mean channel, Mask Filter and Wiener channel as per MSE esteem from Table (4), as a result of the exhibition of Gaussian channel depends on least mean square error. Mean channel functions admirably from Wiener and Mask channel, yet Mask channel performs well for expelling Salt and Pepper commotion and Poisson clamor. As a whole Gaussian channel is best than others.

\section{Conclusion}

Right now, sorts of clamors, (Gaussian, Salt and Pepper, Speckle and Poisson commotion) had been added to the first perfect picture. We see that all commotion causes corruption in the picture quality which brings about loss of data. The filtering of the debased picture is performed utilizing Mean, Gaussian, Mask and Wiener channels. Many picture sifting calculations can be successfully executed with a decreased number of activities per pixel. We have done the examination between various picture sifting calculations.

SNR and PSNR parameter are utilized for execution of factual estimating Wiener channel performs preferable in expelling commotion over different channels. Wiener channel functions admirably for a wide range of clamors. The presentation of Gaussian channel is superior to any thing Mean channel, Mask Filter and Wiener channel as per MSE results. 
In this way, we conclude that Gaussian sifting approach is the best strategy that can be effectively actualized with the assistance of the MSE of picture. The Gaussian channel is evidently superior to different calculations at expelling noise.

SNR, PSNR and MSE have been utilized as statistical performance measurements. Findings of numerical quantities had been recreated with MATLAB.

\section{References}

[1] Arya, M. C., \& Semwal, A. (2017). Comparison on Average, Median and Wiener Filter using Lung Images. International Research Journal of Engineering and Technology , 4 (2), 131-133.

[2] Boyat, A. K., \& Joshi, B. K. (2015). A Review Paper: Noise Models in Digital Image Processing. Signal \& Image Processing: An International Journal , 6 (2), 63-75.

[3] Chandel, R., \& Gupta, G. (2013). Image Filtering Algorithms and Techniques: A Review. International Journal of Advanced Research in Computer Science and Software Engineering , 3 (10), 198-202.

[4] Gopatoti, A., Gopathoti, K. K., Shanganthi, S. P., \& Nirmala, C. (2018). Image Denoising using Spatial Filters and Image Transforms: A Review. International Journal for Research in Applied Science \& Engineering Technology, 6 (4), 3447-3452.

[5] Kaur, P., \& Singh, J. (2011). A Study on the Effect of Gaussian Noise on PSNR Value for Digital Images. International Journal of Computer and Electrical Engineering , 3 (2), 319-321.

[6] Kaur, S. (2015). Noise Types and Various Removal Techniques. International Journal of Advanced Research in Electronics and Communication Engineering , 4 (2), 226-230.

[7] Kaur, S., \& Singh, E. R. (2015). Image De-Noising Techniques: A Review Paper. International Journal for Technological Research in Engineering , 2 (8), 1649-1653.

[8] Kumar, V., \& Gupta, P. (2012). Importance of Statistical Measures in Digital Image Processing. International Journal of Emerging Technology and Advanced Engineering , 2 (8), 56-62.

[9] Makandar, A., \& Halalli, B. (2015). Image Enhancement Techniques using Highpass and Lowpass Filters. International Journal of Computer Applications , 109 (14), 12-15.

[10] Mistry, D., \& Banerjee, A. (2014). Deblurred of Image with Wiener Filter in MATLAB. Journal of Emerging Technologies and Innovative Research , 1 (1), 24-29.

[11] Patidar, P. K., Lalit, Singh, B., \& Bagaria, G. (2014). Image Filtering using Linear and Non Linear Filter for Gaussian Noise. International Journal of Computer Applications , 93 (8), 29-34.

[12] Pushpavalli, R., \& Sivaradje, G. (2012). Switching Median Filter for Image Enhancement. International Journal of Scientific \& Engineering Research , 3 (2).

[13] Rashidi, A., \& Rahimz, M. K. (2016). Extensive Experimental Analysis of Image Statistical Measures for Image Processing Appliances. Journal of Global Research in Computer Science , 7 (1), 4-9. 